\title{
A Current Viscosity of Different Egyptian Crude Oils: Measurements and Modeling Over a Certain Range of Temperature and Pressure
}

\author{
Shaimaa Saeed ${ }^{1 *}$, Tarek M Aboul-Fotouh ${ }^{2}$ and Ibrahim Ashour ${ }^{1,3}$ \\ ${ }^{1}$ Chemical Engineering Department, Faculty of Engineering, Minia University, Egypt \\ ${ }^{2}$ Mining and Petroleum Engineering Department, Faculty of Engineering, Al-Azhar University, Egypt \\ ${ }^{3}$ Environmental Engineering, Zewail city of Science and Technology, 6 of October City, Egypt
}

\begin{abstract}
Viscosity is an important characteristic of crude oil. The viscosity has significant effect for all events in the pipeline transportation of crude oil. The changing in viscosity of crude oil is depending on the temperature, pressure and chemical composition of the crude. In the determination process of crude oil viscosity operations, it is usual to use only temperature dependence of viscosity while the pressure is neglected. Therefore, the essential goal of this study is to obtain a model that can successfully calculate the viscosity in a wide range of temperatures and pressures. Moreover, at this study a mathematical model of changing the current viscosity of Egyptian crude oil with changing of temperature and pressure is determined. Different API gravities of 6 oil samples ranging from 13.4 to 40.4 are tested.

The current viscosity measured at the temperature and pressure ranges from 20 to $140^{\circ} \mathrm{C}$ and from 14.7 to 132.3 psi. These measurements are determined by using the quartz process viscometer apparatus. The comparison between the experimental data and the calculated values is indicated that the proposed model successfully calculate the experimental data with an average absolute percentage relative error of less than 3 and correlation coefficients of 0.991 . It is noted that it's possible to predict a correlation for the dead crude oil viscosity using temperature and pressure change, because the pressure is important for the viscosity and cannot be neglected.
\end{abstract}

Keywords: Current viscosity; Viscometer apparatus; Crude oils; Mathematical; Correlation

\section{Introduction}

The viscosity is important for numerical simulations to determine the economics of the Enhanced Oil Recovery (EOR) projects and the success or failure of a given EOR schemes. The viscosity of crude oil depends on many factors; one of them is the source of chemical composition [1]. So, developing a model of viscosity to include different regions of the world seems to be a very impossible task [2]. Authors in that field are depending on viscosity measurements as interval readings, but this paper is depending on the current readings of viscosity to simulate the reality. So the aim of resent research is the determination of current Egyptian crude oil viscosity as a function of temperatures and pressures and creating mathematical model for this current viscosity with parameters directly indicate compositions which are more valuable and simple to use. In general, the viscosity is defined as the internal resistance of the fluid to flow. The crude oil viscosity is an important physical property that controls and influences the flow of oil through porous media and pipes [3]. Evaluation of viscosity of crude oil is an important for the design of various operations in the crude oil production field. Therefore, the viscosity of crude oil, pressure and temperature dependent, must be evaluated for both reservoir engineering and operation design.

The changing in viscosity with temperature and pressure change is usually predicted empirically. Despite of the importance of viscosity in engineering design, our understanding of such property is inferior to that of equilibrium properties. There are many difficulties in calculating viscosity measurements, especially for olive oil, which is a very important property that should be precisely evaluated for the reservoir simulation. Measuring the viscosity of dead oil is easier using empirical correlations at different temperatures other than the reservoir temperatures. These dead oil measurements are used in calculating live oil viscosity [4]. The difficult and high cost of viscosity measurements at reservoir conditions are the main reason for the weakness of such data. Beal developed a chart that described the viscosities of 655 dead oil samples, representing 492 oil fields around the world and covering viscosities ranging from 0.8 to $155 \mathrm{cP}$, ${ }^{\circ} \mathrm{API}$ gravities from 10.1 to 52.5 and temperatures from $38^{\circ} \mathrm{C}$ to $105^{\circ} \mathrm{C}$. In addition, Kartoatmodjo and Schmidt [5] represented an empirical correlation to predict the viscosity of dead oil with 3588 data points from 661 dead oil samples that covered gravities ranging from 14.4 to $58.9 \mathrm{API}$, viscosities ranging from 0.5 to $682 \mathrm{cP}$, and temperatures ranging from $75^{\circ} \mathrm{F}$ to $320^{\circ} \mathrm{F}$. Labedi [6] also presented the dead oil viscosity in the range of 0.66 to $4.79 \mathrm{cP}$ and ${ }^{\circ} \mathrm{API}$ ranging from 32.2 to 48.0 as a function of API gravity and temperature in the range of 38 to $152^{\circ} \mathrm{C}$ using 91 data points.

Several correlations for predicting dead oil viscosity are available in the literature review and some of them are discussed in this study, the Beggs and Robinson [7] represented a model for temperatures ranging from 21 to $146^{\circ} \mathrm{C}$ and El sharkawy and Alikhan [8] also represented a model based on crude oil samples from the Middle East for temperatures ranging from $38^{\circ} \mathrm{C}$ to $150^{\circ} \mathrm{C}$. Naseri et al. [9] provided model for temperatures ranging from 40 to $146^{\circ} \mathrm{C}$. Many authors decided that, Beal and Beggs and Robinson equations are

"Corresponding author: Shaimaa Saeed, Chemical Engineering Department, Faculty of Engineering, Minia University, Egypt, Tel: +20201093015003; E-mail: engshaimaa24@gmail.com

Received September 07, 2016; Accepted September 30, 2016; Published October 08, 2016

Citation: Saeed S, Aboul-Fotouh TM, Ashour I (2016) A Current Viscosity of Different Egyptian Crude Oils: Measurements and Modeling Over a Certain Range of Temperature and Pressure. J Pet Environ Biotechnol 7: 305. doi: 10.4172/2157 7463.1000305

Copyright: $\odot 2016$ Saeed S, et al. This is an open-access article distributed under the terms of the Creative Commons Attribution License, which permits unrestricted use, distribution, and reproduction in any medium, provided the original author and source are credited. 
Citation: Saeed S, Aboul-Fotouh TM, Ashour I (2016) A Current Viscosity of Different Egyptian Crude Oils: Measurements and Modeling Over a Certain Range of Temperature and Pressure. J Pet Environ Biotechnol 7: 305. doi: 10.4172/2157-7463.1000305

more accurate than previous efforts which might have been true for this viscosity range. However, large errors observed when this model applied outside of these temperatures, viscosity and API ranges. Darko Knežević et al. [10] developed a mathematical model of new correlation for the lubricating oil dynamic viscosity as a function of temperature and pressure. In this work viscosity of Egyptian crude oils with API ranges from 13.4 to 40.4 are measured experimentally over wide range of temperature and pressures and a mathematical model has been developed.

\section{Experimental Study}

The dynamic current viscosity, $\mu$ of dead crude oil for 6 samples in a temperature range from 20 to $140^{\circ} \mathrm{C}$ and pressure range from 14.7 to 132.3 psi is determined using a quartz process viscometer apparatus. The quartz process viscometer consists of two components, the electronic device for control and evaluation and the measuring head. The core of the quartz process viscometer is an oscillating quartz sensor that is subjected to dampening by the viscous properties of the surrounding liquid at the measuring head. The type of the sensor is $\mathrm{SiO}_{2}$ of cylindrical shape with small dimensions. The quartz viscometer's microprocessor contains powerful extrapolation algorithm of the temperature dependent density of the liquid, resulting of a mathematical and physical analysis of the system [11]. Optionally the viscometer can be supplied with a high pressure sample container, which can be used to measure the viscosity of pressurized samples up to $100 \mathrm{bar}(1450 \mathrm{psi})$ at a maximum temperature of $150^{\circ} \mathrm{C}\left(300^{\circ} \mathrm{F}\right)$ as shown in Figure 1. Moreover, the steps for how to use this apparatus are illustrated in Figure 2. These steps are expressed as the following:

1. The sample is filled into the pressure cell (1)

2. Inside the pressure cell a crude oil level of $100 \mathrm{ml}$ is marked (10)

3. The formation of a vortex due to a stirrer with $(200 \mathrm{r} / \mathrm{m})$ found so recommended to fill in some more fluid $(\sim 103 \mathrm{ml})$.

4. The sensor head is screwed into the closure head from the below using a suitable copper gasket (3).

5. Before closing the unit, please place the O-ring seal (2) in the notch on the inner side.

6. A location bolt (4) shows the correct orientation of the flange lid; please make sure that the pin enters the corresponding bore (5).

7. After closing the unit, use the 8 screws (6) to close and fix the pressure cell.

8. To improve the temperature regulation, a customizedinsulation jacket (11) can be supplied.

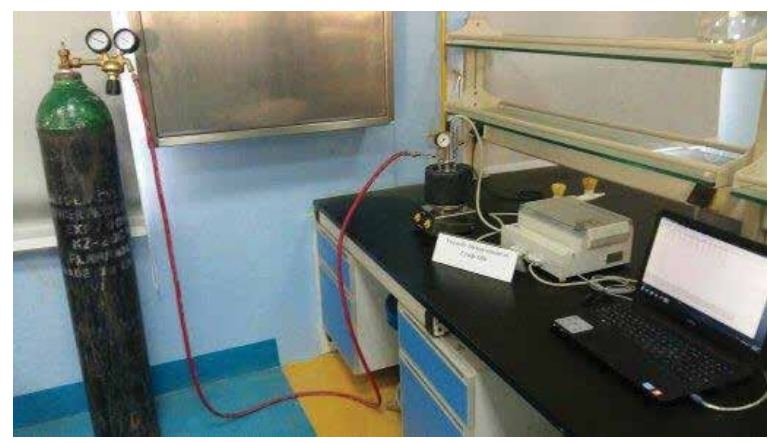

Figure 1: The process viscometer apparatus in the laboratory.

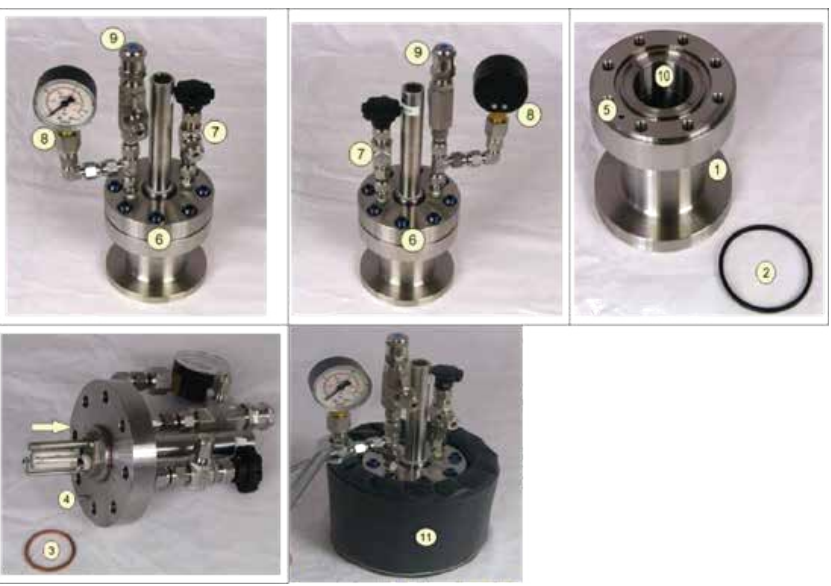

Figure 2: Steps of measurements in the process viscometer apparatus.

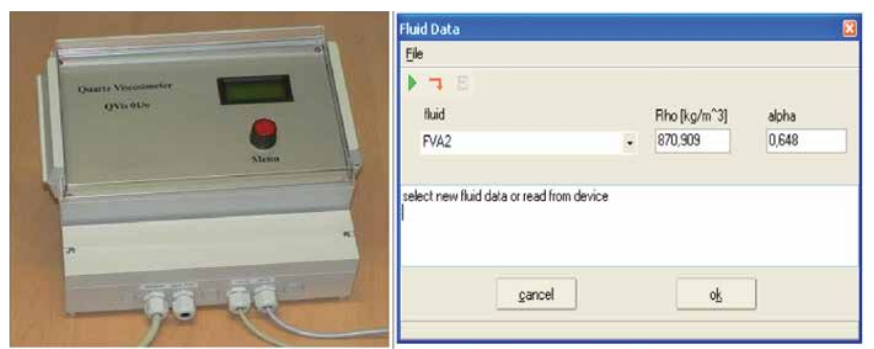

Figure 3: The control unit of the process viscometer apparatus.

9. The needle valve (7) is used to pressurize the unit. The pressure inside the unit is displayed on the pressure gauge (8).

10. For safety reasons an overpressure valve (9) is part of the unit. For the control unit:

At the lower border of the main window is the status line, which displays the settings of "the current measurement" (Figure 3):

- Given density.

- Given coefficient of thermal expansion

- Name of the fluid (if known).

- Number of measurements (or start temperature or measurement duration).

- Stop temperature.

- Temperature (or time) step.

According to the density extrapolation of the samples the process viscometer need to introduce thermal expansion factor ( $\alpha$ ) which calculated from the following equation (1):

$\rho t=\rho 15-(t f-t 15)$

Where:

$\rho t$ is the density of the fluid at final temperature in $\mathrm{Kg} / \mathrm{m}^{3}$,

$\rho 15$ is the density of the fluid at $15.5^{\circ} \mathrm{C}$,

$\alpha$ is thermal expansion coefficient, 
$t f$ is the final temperature of the fluid,

t15 is the temperature of the fluid at $15.5^{\circ} \mathrm{C}$.

Every crude oil gravity has certain $(\alpha)$ introduced in the beginning of process measurements. The measurements based on time step as you prefer (ex.: every $15 \mathrm{sec}$ ). Also magnetic stirrer is used in samples at 200 revolutions per minute $(\mathrm{r} / \mathrm{m})$ (current measurements). After recording the reading of runs from the apparatus, the Figures between the viscosities versus temperatures are plotted. Table 1 describes the data used with these runs. In addition, the chemical composition of the crude oil is related to (specific gravity and Watson characterization factor). And The Watson factor is related to the average boiling point and API gravity of the crude oil through the following relation [12]:

$$
K w=\left(131.5+\text { API141.5) }\left(T_{b}\right) 1 / 3\right.
$$

In the correlations which utilizing the Watson characterization factor, we follow the procedure of Twu [13] for the estimation of dead oil viscosity; which can be briefed as follows:

$$
\mu o d=\gamma o T * v T
$$

$\gamma_{o T}$ is the crude oil specific gravity at temperature $\mathrm{T}$ and is given by the following relation

$$
\gamma_{\mathrm{oT}}=0.999012\left(\gamma_{o 60} V C F_{T}\right)
$$

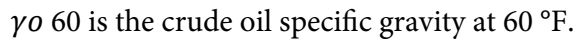

$V C F_{T}$ is the crude oil volume correction factor at $60^{\circ} \mathrm{F}$ :

$$
V C F_{T}=\boldsymbol{e}^{[-\alpha 60 \Delta(\mathbf{1}+\mathbf{0 . 8} \propto 60 \Delta \boldsymbol{T})]}
$$

$\propto_{60}$ is the thermal expansion coefficient at $60^{\circ} \mathrm{F}$ :

$$
\alpha_{60}=\frac{K_{0}+K_{1} \gamma_{060}}{\gamma_{060}^{2}}
$$

In the quartz process viscometer apparatus, the thermal expansion factor and the density in $\mathrm{g} / \mathrm{cm}^{3}$ (specific gravity) of the crude oil at $60^{\circ} \mathrm{F}$ are essential input parameters for each run. Hence, the apparatus automatically apply this rule in its calculations for the current viscosity in experimental data. So, the composition is taking into consideration in the 5 recent model and the calculated parameters (constants) of the recent model are directly indicated the composition.

\section{Results and Discussion}

\section{The new model}

The experimental data of the dynamic current dead oil viscosity of 6 samples with different API values is measured with in the temperature range and pressure range of $\left(20^{\circ} \mathrm{C}\right.$ to $\left.150^{\circ} \mathrm{C}\right)$, (14.7 to $\left.132.3 \mathrm{Psi}\right)$. The ASTM shows that dead oil viscosity is classified according to its standard API at $15.5^{\circ} \mathrm{C}$ which is the first parameter for any model, and the second parameter is the value of the measured temperature $[14,15]$. According to literature review, most of the previous models are based

\begin{tabular}{|c|c|}
\hline Variable & Range \\
\hline API & 13.4 to 40.4 \\
\hline Temperature $\left({ }^{\circ} \mathrm{C}\right)$ & 20 to 140 \\
\hline Pressure $(\mathrm{psi})$ & 14.7 to 132.3 \\
\hline Density $\left(\mathrm{g} / \mathrm{cm}^{3}\right)$ & 808.8 to 975.6 \\
\hline Thermal expansion factor $(\alpha)$ & 0.65 to 0.7 \\
\hline Revolution $/$ minute $(\mathrm{r} / \mathrm{m})$ & 200 \\
\hline
\end{tabular}

Table 1: Description of data used with samples. on, sometimes two parameters, the API and temperature to calculate the dead viscosity. In most cases, API parameter has no physical meaning [16] Therefore, another parameter is used with temperature, such as pressure. The objective is to create a model in the following formats to calculate the dead oil viscosity.

$$
\mu_{o d} \propto(T,)
$$

Where: $\mu_{o d}$ is the dead oil viscosity in $\mathrm{cP}$,

$T$ is the temperature in ${ }^{\circ} \mathrm{C}$,

$P$ is the pressure in psi.

Before creating the new current viscosity model, understanding the relationship. Between the input and output variables is important. Specifically, identifying which parameters are insignificant and can be eliminated from the final model and the parameters that are highly correlated with the output. Accordingly, the current dead oil viscosity ( $\mu \mathrm{od})$ is considered to be a function of temperature $(\mathrm{T})$ and pressure (P). As shown in plotting the data yields Figure 4. It illustrates how viscosity changes according to temperature and pressure changes. As illustrated in Figure 4 the viscosity decreasing by increasing temperature and when measuring the viscosity at different pressures are observed that the value of viscosity increased by increasing the pressure at certain API. More addition, due to the samples of crude oils is prepared from different Egyptian company's fields so there is a difference in composition. Figure 5 illustrates the relationship between current viscosity and frequency (the frequency is a parameter given by the quartz viscometer apparatus) for every run at $(0.3,6.9$ bar) and $200 \mathrm{r} / \mathrm{m}$. Additionally, it shows decreasing in current viscosity with increasing the frequency of the fluid. Moreover, Reynolds Number is calculated at temperature intervals $\left(50^{\circ} \mathrm{C}, 100^{\circ} \mathrm{C}, 150^{\circ} \mathrm{C}\right)$ from the following relation to know the type of flow [17].

$$
\mathrm{N}_{\mathrm{Re}}=D N \rho / \mu
$$

Where: $\mathrm{D}$ is the inside diameter of the crude cylinder in the quartz process viscometer.

$$
\begin{aligned}
& \mathrm{N}=\text { The agitator speed (rph). } \\
& \rho=\text { The density of the crude given by the apparatus. } \\
& \mu=\text { The viscosity of the crude given by the apparatus } \\
& \text { The NRe }>10,000 \text { the flow is turbulent. }
\end{aligned}
$$

\section{The validity of the new viscosity model}

After testing many previous viscosity equations for all the experimental viscosity data for this study as a function of pressure and temperature, the results show that the following equation is set to be presented the data in this work and give us correlation coefficients (R2) up to 0.99 as follow:

$$
\mu_{0 d}(\mathrm{P}, \mathrm{T})=\mathrm{ae}^{\left[\frac{b}{(T-c)}\right]} e^{\left[P /\left(a_{1}+a_{2} T\right)\right]}
$$

Where: $\mu_{o d}$ is the dynamic viscosity in $\mathrm{cp}, \mathrm{T}$ is the temperature in ${ }^{\circ} \mathrm{C}$ and $\mathrm{P}$ is the pressure in psi. (a, b, c, a1, a2) are constants (parameters directly indicate composition). The model can predict the current dead oil viscosity with an average percentage absolute relative error (AARE) of $3 \%$ and correlation coefficient (R2) of 0.991 . The results are evaluated and tested using different techniques. One of the main challenges in this study is that most of the existing models in the literature are limited to certain ranges of temperature, API value. But this study represents the current viscosity at different ranges of temperatures and pressures with 
Citation: Saeed S, Aboul-Fotouh TM, Ashour I (2016) A Current Viscosity of Different Egyptian Crude Oils: Measurements and Modeling Over a Certain Range of Temperature and Pressure. J Pet Environ Biotechnol 7: 305. doi: 10.4172/2157-7463.1000305

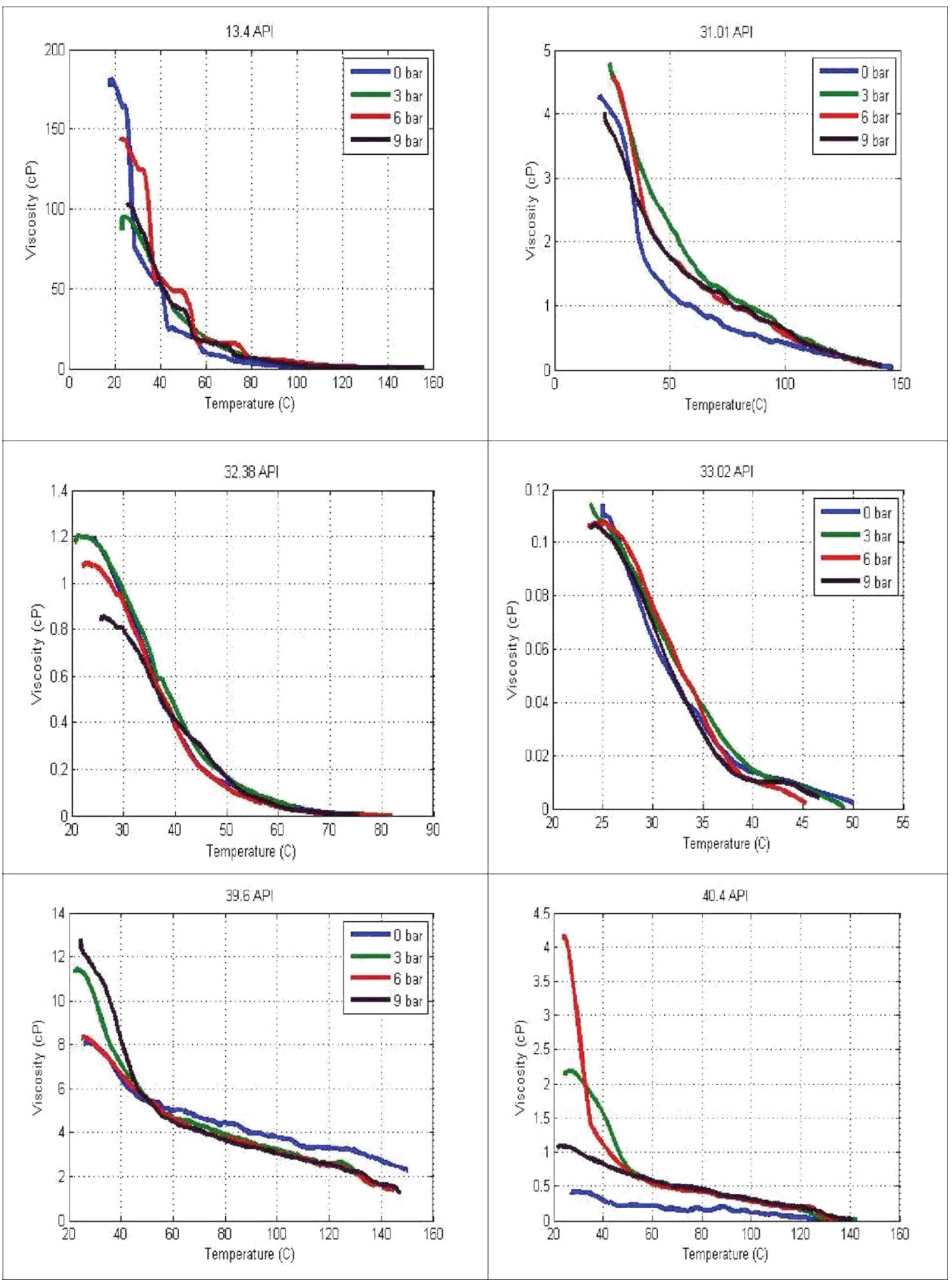

Figure 4: Experimental data of different Egyptian crude oil samples viscosities.

constant parameters which directly indicate composition.

Table 2 indicates the values of ( $a, b, c, a 1, a 2)$ related to each run of the data set. To check the ability of the new current viscosity model to indicate all experimental data, cross plots are used. The values are in a good agreement, with the average percentage absolute relative error and standard division comparing with previous models as indicated in Table 3. Table 4 indicates the evaluation of the new model for prediction of the current dead oil viscosity. In addition, the absolute percentage average relative error (AARE\%) and the standard percentage deviation $(\mathrm{SD} \%)$ tests are performed between the calculated and the measured 
Citation: Saeed S, Aboul-Fotouh TM, Ashour I (2016) A Current Viscosity of Different Egyptian Crude Oils: Measurements and Modeling Over a Certain Range of Temperature and Pressure. J Pet Environ Biotechnol 7: 305. doi: 10.4172/2157-7463.1000305

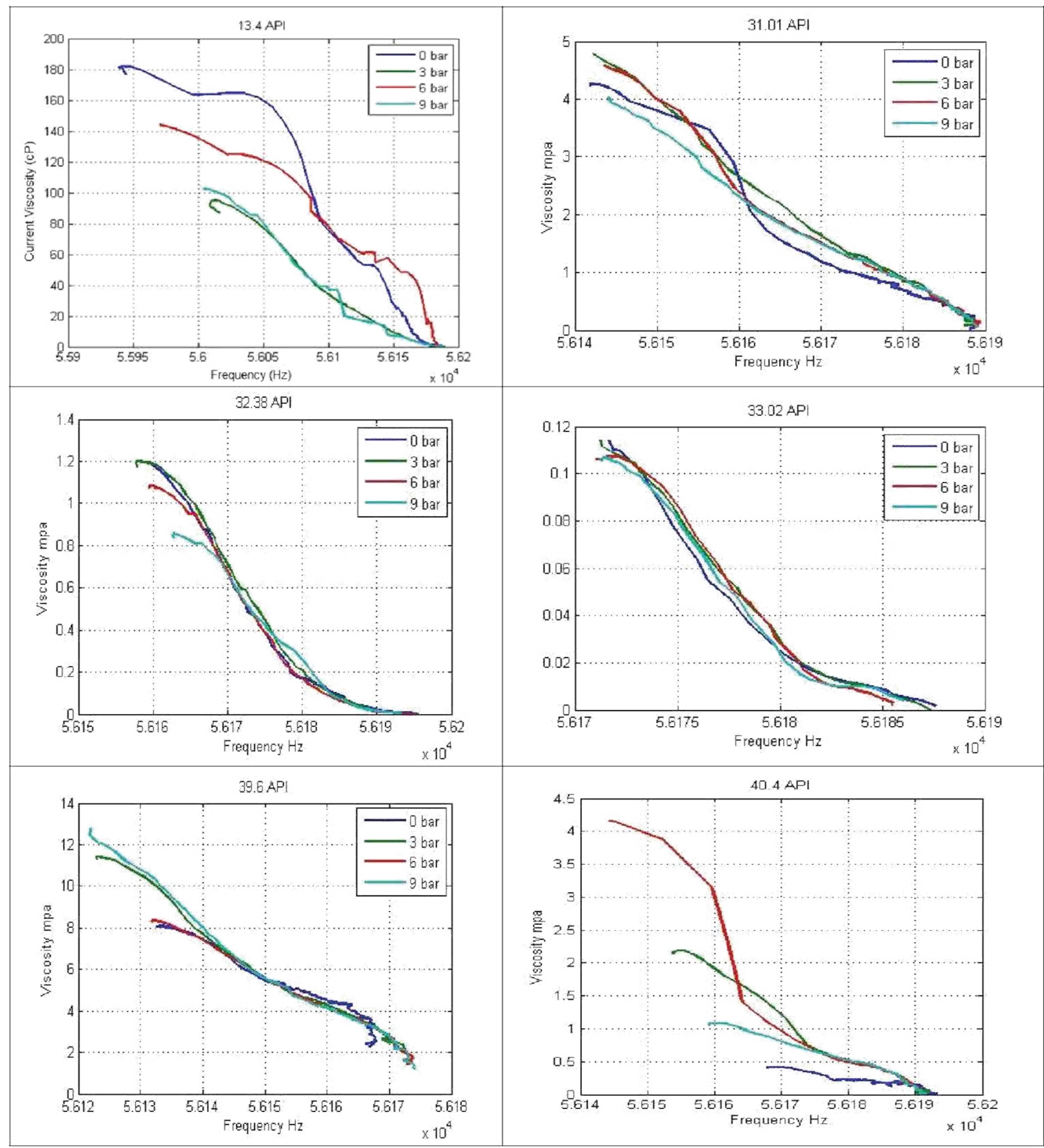

Figure 5: Experimental data of different Egyptian crude oil samples viscosities.

results by the following expressions:

$$
A A R E \%=\left|\frac{(\text { measured }- \text { calculated })}{\text { measured }}\right| * 100
$$

$$
S D=\frac{1}{1-N} \sqrt{\sum_{i=1}^{N}\left(\left|\frac{\text { measured }- \text { calculated }}{\text { measured }}\right|-A A R E\right)} 2
$$

Where: $i$ is the sample number and $N$ is the total number of samples.

The new model shows the lowest average percentage absolute 
Citation: Saeed S, Aboul-Fotouh TM, Ashour I (2016) A Current Viscosity of Different Egyptian Crude Oils: Measurements and Modeling Over a Certain Range of Temperature and Pressure. J Pet Environ Biotechnol 7: 305. doi: 10.4172/2157-7463.1000305

Page 6 of 8

\begin{tabular}{|c|c|c|c|c|c|}
\hline \multirow{2}{*}{$\begin{array}{l}\text { Parameters } \\
\text { (directly } \\
\text { indicate } \\
\text { composition) }\end{array}$} & \multicolumn{4}{|c|}{ Values of parameters at different pressures (Psi) } & ${ }^{\circ} \mathrm{API}$ \\
\hline & 14.7 & 44.1 & 88.2 & 132.2 & \multirow{6}{*}{13.4} \\
\hline a & 1.007 & 0.000212 & 6.475 & 2.717 & \\
\hline b & -20.38 & 4.405 & 102.7 & 115.7 & \\
\hline c & -1.897 & -0.6139 & -9.704 & -5.272 & \\
\hline a1 & 1.469 & -10.28 & -2241 & -4769 & \\
\hline a2 & 0.04793 & 1.491 & 239 & 483.6 & \\
\hline a & 0.9112 & 0.9423 & 0.0293 & 1.006 & \multirow{5}{*}{39.6} \\
\hline b & 0.142 & 3.759 & 0.0085 & -4349 & \\
\hline c & -376.3 & -1105 & 26.11 & 0.7489 & \\
\hline a1 & 5.301 & 11.57 & 14.35 & 0.4612 & \\
\hline a2 & 0.0538 & 0.2569 & 0.0488 & 0.24 & \\
\hline a & 0.3132 & 0.0043 & 0.0017 & 0.00603 & \multirow{5}{*}{31.01} \\
\hline b & 65.56 & -0.00346 & -0.001 & 302.1 & \\
\hline c & -5.811 & 26.1 & 25.45 & -139.7 & \\
\hline a1 & -7.439 & 5.511 & 9.61 & 24.52 & \\
\hline a2 & 5.435 & 0.0324 & 0.0583 & 0.1663 & \\
\hline a & 0.00017 & 0.0044 & 511.6 & 4.585 & \multirow{5}{*}{33.02} \\
\hline b & 0.7921 & 26.34 & 161.8 & 1395 & \\
\hline c & 0.6613 & 57.57 & 63.64 & 239.4 & \\
\hline a1 & 0.8194 & 9.282 & -17.72 & -10.79 & \\
\hline a2 & 0.0576 & 0.0796 & -0.121 & 2.401 & \\
\hline a & $1.08 \mathrm{E}-06$ & 0.00323 & 0.0704 & $3.34 \mathrm{E}-06$ & \multirow{5}{*}{40.4} \\
\hline b & -0.0124 & -2.86 & 125.6 & 0.00297 & \\
\hline c & 26.97 & 19.82 & -6.978 & 21.67 & \\
\hline a1 & 1.078 & 4.876 & 625 & 9.934 & \\
\hline a2 & 0.002261 & 0.05478 & 22.28 & 0.0183 & \\
\hline$a$ & 0.05061 & 0.07867 & 0.0368 & $1.21 \mathrm{E}-07$ & \multirow{5}{*}{32.38} \\
\hline b & -34.77 & -89.97 & -86.09 & -28.9 & \\
\hline c & 4.174 & 2.507 & 8.988 & 13.2 & \\
\hline a1 & -0.1303 & -0.208 & -2.118 & 5.831 & \\
\hline a2 & 0.1268 & 0.2811 & 0.4903 & 0.05881 & \\
\hline
\end{tabular}

Table 2: The values of modeling parameters at different pressure and API

\begin{tabular}{|c|c|c|}
\hline References & $\begin{array}{c}\text { Average absolute } \\
\text { relative error \% } \\
\text { (AARE \%) }\end{array}$ & $\begin{array}{c}\text { Standard } \\
\text { deviation\% } \\
\text { (SD \%) }\end{array}$ \\
\hline Beal & 31.6 & 37.3 \\
\hline Beggs and Robinson & 21.2 & 28.0 \\
\hline Glaso & 27.4 & 31.9 \\
\hline Labedi & 29.7 & 42.6 \\
\hline Kartoatmodjo and Shmidt & 33.1 & 37.25 \\
\hline Ibrahim Ashour & 19.2 & 25.8 \\
\hline Osama Alomair & 8 & 203.7 \\
\hline
\end{tabular}

Table 3: Average absolute relative error and standard deviation of previous model.

relative error and standard percentage deviations relative to the others. Figure 6 shows the behavior of a new model according to the experimental and calculated values. The new model provides the best prediction without any scattering between the experimental data and the calculated one, thus the new model presents high value of correlation coefficient. Figure 6 consists of plots for 6 samples at (13.4, $31.01,32.38,33.02,39.6,40.4)$ API.

\section{Conclusion}

Although, crude oils of different compositions can have the same
${ }^{\circ}$ API gravity, significant errors may be introduced when the viscosities of crude oils are estimated from general viscosity trends and the API gravity. The new current dead oil viscosity model is a function of temperature $\mathrm{T}$ and pressure $\mathrm{P}$ with constant parameters that directly indicate composition which are more valuable and simple to use. Impossible to find any similarity between this study and previous one because all measurements are current viscosity, the crude oil is in continues motion in the apparatus at 200 revolutions per minute $(\mathrm{r} / \mathrm{m})$. The temperature is increased automatically up to $150^{\circ} \mathrm{C}$ and the reading is taken automatic with time step as the user prefer. The pressure range used is chosen to unique the pressure inside the pipe line which the fluid (crude oil) is transferred across. So, this process is simulated to the reality. The validity of the agreement between the experimental current dead oil viscosity data and the predicted values indicates that the new model successfully represents the experimental data with an average percentage absolute relative error less than $3 \%$ and correlation coefficients ranging from 0.99 to 0.94 at different temperatures and pressures. From the statistical analysis, the new model is present as one of the best models by comparing it with other models published in the literature. The new model shows it is easy to use different temperatures

\begin{tabular}{|c|c|c|c|c|}
\hline API & Pressure (psi) & $\begin{array}{l}\text { Average Absolute } \\
\text { Relative Error } \\
\text { (AARE\%) }\end{array}$ & $\begin{array}{l}\text { (Standard } \\
\text { Deviation) } \\
\text { SD \% }\end{array}$ & R2 \\
\hline \multirow{4}{*}{13.4} & 14.7 & 0.056 & 0.00452 & 0.9739 \\
\hline & 44.1 & 0.144 & 0.937 & 0.9186 \\
\hline & 88.2 & 0.1756 & 0.474 & 0.8867 \\
\hline & 132.3 & 0.1037 & 0.856 & 0.918 \\
\hline \multirow{4}{*}{31.01} & 14.7 & 0.0792 & 0.0023 & 0.886 \\
\hline & 44.1 & 0.03 & 0.0388 & 0.9862 \\
\hline & 88.2 & 0.0078 & 0.00569 & 0.9881 \\
\hline & 132.3 & 0.0199 & 0.0302 & 0.9798 \\
\hline \multirow{4}{*}{32.38} & 14.7 & 0.0772 & 0.3135 & 0.9138 \\
\hline & 44.1 & 0.116 & 0.4587 & 0.8327 \\
\hline & 88.2 & 0.1377 & 0.177 & 0.9007 \\
\hline & 132.3 & 0.0826 & 0.5554 & 0.991 \\
\hline \multirow{4}{*}{33.02} & 14.7 & 0.0557 & 0.725 & 0.9784 \\
\hline & 44.1 & 0.3047 & 4.36 & 0.9285 \\
\hline & 88.2 & 0.0787 & 1.127 & 0.9665 \\
\hline & 132.3 & 0.1876 & 2.502 & 0.9207 \\
\hline \multirow{4}{*}{39.6} & 14.7 & $8.12 \mathrm{E}-05$ & 0.00019 & 0.9787 \\
\hline & 44.1 & 4.95E-05 & $1.95 \mathrm{E}-05$ & 0.9897 \\
\hline & 88.2 & 0.00068 & 0.000652 & 0.9879 \\
\hline & 132.3 & 0.00632 & 0.00998 & 0.9844 \\
\hline \multirow{4}{*}{40.4} & 14.7 & 0.00451 & 0.00134 & 0.9304 \\
\hline & 44.1 & 0.00804 & 0.00763 & 0.9876 \\
\hline & 88.2 & 0.0413 & 0.0213 & 0.9744 \\
\hline & 132.3 & 0.0315 & 0.0917 & 0.9522 \\
\hline
\end{tabular}

Table 4: Accuracy of Egyptian crude oil model for estimating viscosity of recent study. 
Citation: Saeed S, Aboul-Fotouh TM, Ashour I (2016) A Current Viscosity of Different Egyptian Crude Oils: Measurements and Modeling Over a Certain Range of Temperature and Pressure. J Pet Environ Biotechnol 7: 305. doi: 10.4172/2157-7463.1000305

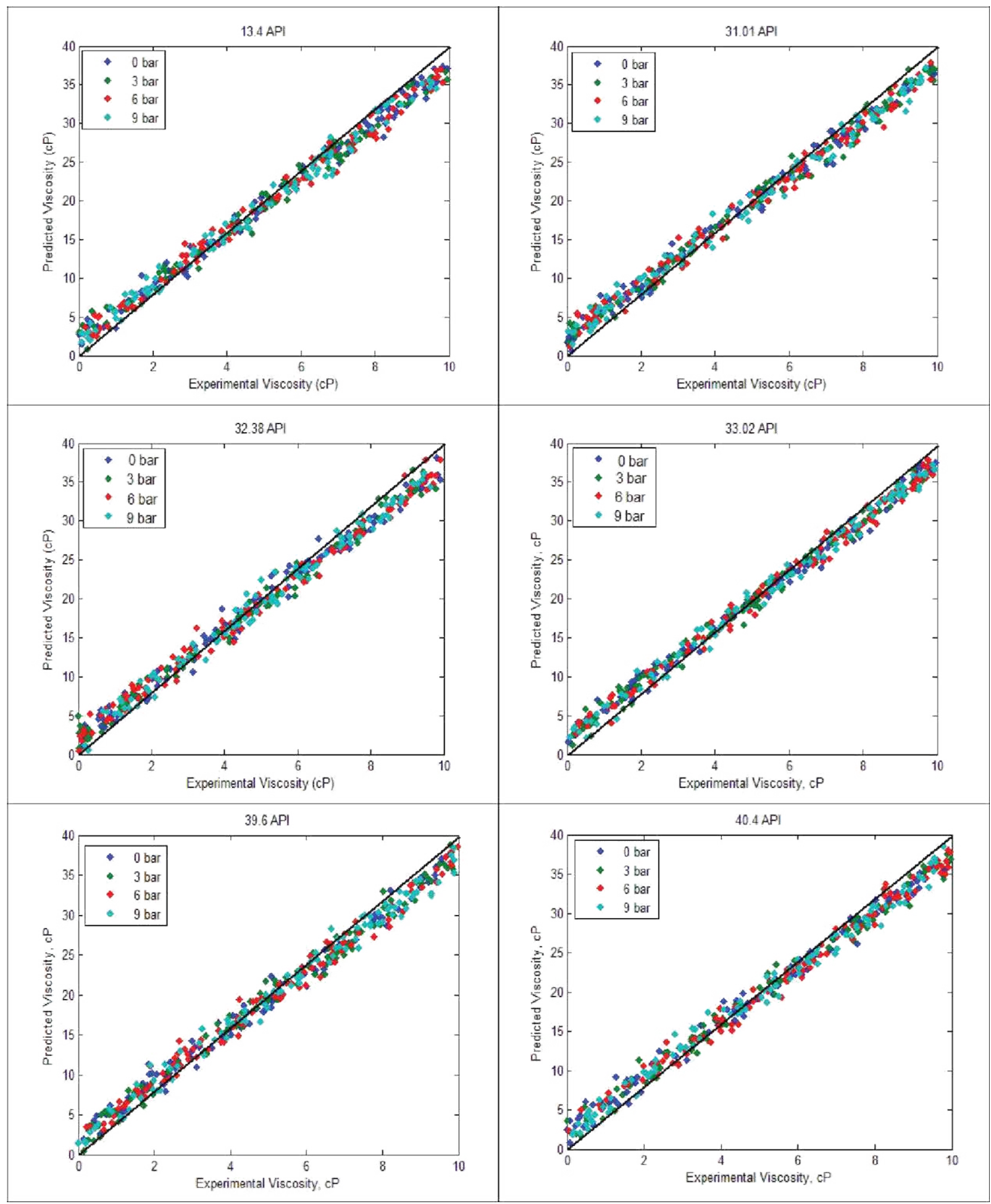

Figure 6: Deviation of experimental current viscosity data from predictive values using the new model.

and pressures to predict current viscosity, provide best accuracy over a wide range of oil gravities, and could be used to predict better outcomes in future works.

\section{References}

1. Ahrabi F, Ashcroft SJ, Shearn RB (1987) High pressure volumetric phase composition and viscosity data for a North Sea crude oil and NGL mixtures. Chem Eng Res 67:329-334

2. Ashour I, Al-Rawahi N, Vakili-Nezhaad G, Fatemi A (2012) A new correlation for prediction of viscosities of Omani-Fahud-Field Crude Oils.

3. Sattarin M, Modarresi H, Bayat M, Teymori M (2007) New viscosity correlations for EAD crude oils. Pet Coal 49: 33-39. 
Citation: Saeed S, Aboul-Fotouh TM, Ashour I (2016) A Current Viscosity of Different Egyptian Crude Oils: Measurements and Modeling Over a Certain Range of Temperature and Pressure. J Pet Environ Biotechnol 7: 305. doi: 10.4172/2157-7463.1000305

Page 8 of 8

4. Beal C (1946) Viscosity of air, water, natural gas, crude oil and its associated gases at oil field temperature and pressures. Trans. AIME 165: 114-127.

5. Kartoatmodjo F, Schmidt Z (1994) Large data bank improves crude physical property correlation. Oil Gas J. 4: 51-55.

6. Labedi R (1992) New viscosity correlations for dead crude oils J Pet Sci Eng. 8: 221-234.

7. Beggs HD, Robinson JR (1975) Estimating the viscosity of crude oil systems. JPT 9: 1140-1141.

8. Elsharkawy AM, Alikhan AA (1999) Models for predicting the viscosity of Middle East crude oils. Fuel 78: 891-903.

9. Naseri A (2005) A correlation approach for prediction of crude oil viscosities. S.A.: J. of Pet. Sci. Eng. 47: 163-174.

10. Knežević D, Savić V (2006) Mathematical modeling of changing of dynamic viscosity, as a function of temperature and pressure, of mineral oils for hydraulic systems UDC 532.12: 665.6. FACTA UNIVERSITATIS 4: 27-34.
11. F5 Technologie GmbH Im Büchenorte 3 D-31515 Wunstorf, Germany.

12. Hassan Naji S (2011) The dead oil viscosity correlations a C-sharp simulation approach JKAU: Eng. Sci. 22: 61-87.

13. Twu CH (1985) Internally consistent correlation for predicting liquid viscosities of petroleum fractions. Ind. Eng. Chem. Process Des. Dev. 34: 1287-1293.

14. Alomair O (2015) Heavy oil viscosity and density prediction at normal and elevated temperatures. J of Pet Exploration and Production Technology 6: 253263.

15. Mehrotra AK (1991) Generalized one parameter viscosity equation for light and medium hydrocarbon. Ind Eng Chem Res 30: 1367-1372.

16. Standing MB (1947) A pressure-volume-temperature correlation for mixtures of California oils and gases. Drill Prod Pract, American Petroleum Institute, New York, pp. 275-284.

17. John Pietranski $F(2012)$ Mechanical agitator power requirements for liquid batches. (PDH online Course K103, $2 \mathrm{PDH}$ ). 